\title{
Quasi-equilibrium Processes of Relaxation of the Electronic Excitation of the Azidomalachite Green Molecule
}

\author{
P.O. Kondratenko ${ }^{1}$, Yu.M. Lopatkin ${ }^{2}$, T.M. Sakun ${ }^{1}$ \\ ${ }_{1}^{1}$ National Aviation University, 1, Guzar Ave., 03058 Kyiv, Ukraine \\ 2 Sumy State University, 2, Rymsky-Korsakov St., 40007 Sumy, Ukraine
}

(Received 17 June 2020; revised manuscript received 15 October 2020; published online 25 October 2020)

\begin{abstract}
Real prospects of application of results of scientific investigations for creation of element base of optoelectronics, development of luminescent sensors, for optical record of the information is the substantiation of urgency of studying the processes connected with electronic highly excited states of molecules. Based on the studies of physical and photochemical processes in solutions of para-azidomalachite green (AMG), it is shown that the absorption spectra of AMG are formed by $\pi \rightarrow \pi^{*}$ quantum transitions. Among the intense absorption bands is a weak absorption band $\pi \rightarrow \sigma^{*}\left(S_{0} \rightarrow S_{3}\right.$ quantum transition). It turned out that the corresponding singlet and triplet states of the molecule are characterized by dissociative energy surfaces, that is, there are two channels of photodissociation of the AMG molecule. It is shown that the processes of relaxation of the excitation of the AMG molecule, which occur with the involvement of high-frequency vibrations of $\mathrm{C}-\mathrm{H}$ bonds, localized on the phenyl rings, proceed as quasi-equilibrium processes. That is, during the relaxation the electronic system of excitation stops at each energy level for a time that exceeds the period of the specified fluctuation. This fact provides the possibility of the processes of dissociation of the molecule from the corresponding energy states. With the increase in temperature from $77 \mathrm{~K}$ to $300 \mathrm{~K}$, the role of high-frequency vibrations of $\mathrm{C}-\mathrm{H}$ bonds increases significantly, that leads to a significant decrease in the quantum yield of AMG photodissociation from both singlet and triplet dissociative states.
\end{abstract}

Keywords: Highly excited electronic states, Photodissociation, Quasi-equilibrium relaxation processes, Para-azidomalachite green, Two channels of photodissociation of a molecule.

\section{INTRODUCTION}

The behavior of molecules in highly excited states is an urgent fundamental problem of modern physics and technology. So far, very little attention has been paid to the relaxation processes of molecular excitation. It was believed that the laws of photochemistry work steadily, and in particular, one of them (the fourth law) states that only the molecules excited in $S_{1}$ or $T_{1}$ are involved in the majority of photochemical processes occurring in solutions of organic molecules [1].

It has long been thought that it should be, since relaxation processes are mostly fast $\left(\sim 10^{-12} \mathrm{~s}\right)$ and nonequilibrium, and all possible equilibrium processes can occur only with the participation of $S_{1}$ or $T_{1}$ states of the molecule. And this despite that the fact of fading of dyes on tissues under the influence of direct sunlight is well known. Subsequently, numerous experimental data emerged to show that the processes of excitation relaxation do not interfere with the flow of processes important in science and practice in highly excited states: generation of current carriers, photochemical and radiation-chemical processes, etc.

For example, a study of the photoconductivity of crystals of linear polyacenes (anthracene, tetracene, pentacene) [2] showed that its high quantum efficiency is observed only when irradiated into highly excited states of molecules in which holes and free electrons are possible. Therefore, during the relaxation of a highly excited state, the excitation of a molecule may stop at an intermediate state that corresponds to the electron transfer between the molecule and the crystal. The processes of charge separation in the non-equilibrium relaxation of a highly excited state have been consid- ered theoretically in Onsager's writings [1].

Similarly, studies of photochemical processes in methylene blue, carried out in $[2,3]$, showed that the dye has no photochemical activity in the long-wavelength absorption band $(\lambda=667 \mathrm{~nm})$ at low excitation intensities. At the same time, it has photochemical activity at high intensities (two-quantum processes) of visible light, or at arbitrary intensities in the ultraviolet region of the spectrum $(\lambda \leq 330 \mathrm{~nm})$. Therefore, the photochemical transformations of the molecule are carried out in a highly excited state.

In the works of the authors of this article [2, 4, 5], the photochemical processes in highly excited states of methylene blue dyes and resazurin were investigated. It has been shown that the relaxation processes in a highly excited molecule proceed by a quasi-equilibrium mechanism. Therefore, in the process of relaxation of excitation, it is possible to stay at energy levels during several vibrations of atoms in a molecule. This is sufficient to allow photochemical processes to occur from the intermediate highly excited state of the molecule. The effect can be achieved by exciting the molecule directly into the active state of the molecule by light with a wavelength $\lambda_{c r}$ (the critical radiation wavelength). When the molecules are excited by light with wavelength $\lambda>\lambda_{c r}$, the photochemical action of light is absent.

Another group of known processes that accompany the relaxation of molecules from a highly excited state is the fluorescence of the $S_{2} \rightarrow S_{0}$ type in solutions of azulene molecules and polymethine dyes [1]. The specificity of the energy structure of these molecules lies in the fact that they are characterized by a large energy distance between the states $S_{2}$ and $S_{1}$, which makes channel of radiation-free relaxation non-competitive. 
A third group of processes is known in the study of the spectral sensitivity of the processes of photodissociation of azidomalachite green (AMG) [6]. In this case, it was found that when the solution of the indicated azide was irradiated by monochromatic light from the region of the long-wavelength absorption band, the quantum yield of photodissociation did not exceed 0.01 . Whereas, the quantum yield of photodissociation increased (almost to one at low temperatures) when this solution was irradiated with light of $\lambda<\lambda_{c r}\left(\lambda_{c r}=350 \mathrm{~nm}\right)$.

The authors were interested in the unusual photochemical activity of para-AMG. Therefore, in this work, we investigated in this molecule the mechanisms of quasi-equilibrium excitation relaxation, which caused an unusual nature of the photoconversion of the molecule.

\section{RESEARCH METHODOLOGY}

The properties of excited states of molecules are investigated by analyzing radiation and photochemical properties, as well as using quantum-chemical methods [1].

Recently, interest in quantum-chemical calculations, which allow us to understand more deeply the physical processes occurring in excited states, as well as the nature of intermolecular interaction, has increased significantly.

Methods of quantum physics and chemistry allow to obtain such microscopic properties of systems as the distribution of electron density in atoms, the degree of hybridization of molecular orbits, the value of various contributions to the energy of interaction, etc., which either by experimental methods or by methods of statistical physics cannot be explored. Therefore, quantum-chemical calculations have an independent significance in the study of various tasks and the solution of problems. Limitations are mainly related to the level of development of computer technology, the use of which is necessary for solving tasks of this kind.

In practice, they use semi-empirical methods more often than more sophisticated ab initio methods, which require much more (several orders of magnitude) machine time than non-empirical methods.

In recent years, MNDO-like methods (NDDO approximations), which include MNDO, AM1 and PM3, are the most widely used of all semi-empirical methods [1].

All three methods are slightly different from each other and give approximately the same (quite satisfactory) results.

For carrying out quantum-chemical calculations in the work, the whole complex of programs was used. This includes the molecular dynamics method, the DFT method [7], and the semi-empirical methods MNDO/d and AM1. The latter allows us to quickly obtain scientific results that lead to the same conclusions as when using the DFT method. When using semi-empirical methods, a configuration interaction between 12 occupied MOs and 12 free MOs was specified. To find the location of charges, log files were used, which are recorded by the computer program during the calculation of the energy characteristics of the molecule.

\section{RESULTS AND DISCUSSION}

In this work, the authors studied the physical and photochemical properties of AMG of the formula

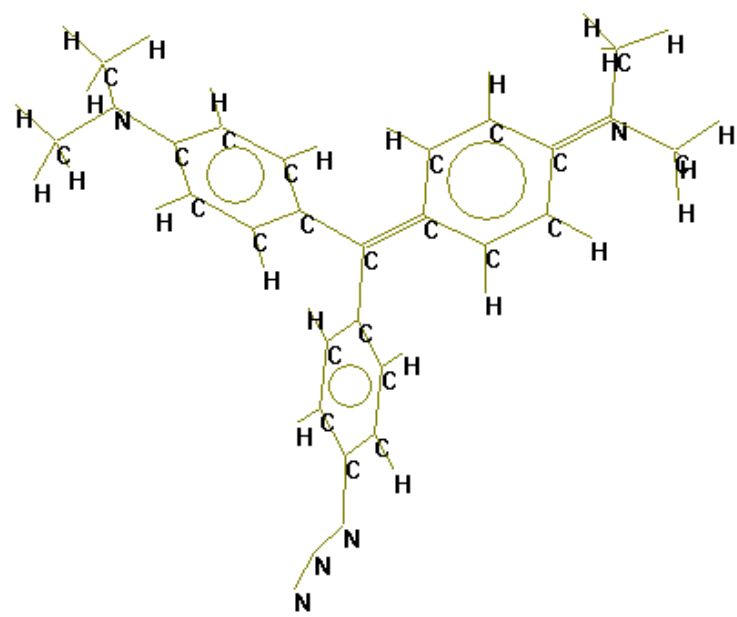

Note that the AMG molecule under study here is represented by a cation that has an even number of electrons. The anion is $\mathrm{ClO}_{4}^{-}$. In this case, this is an important point since the molecule is always in a dissociated state providing a virtually unchanged absorption spectrum during the transition from liquid to solid dye solutions. Studies show that replacing the anion with $\mathrm{Cl}^{-}$leads to the association of the dye, resulting in the hybridization of the central carbon atom changing from $s p^{2}$ to $s p^{3}$. As a consequence, the $\pi$-electron system breaks down and the absorption spectrum shifts to the ultraviolet region.

The phenyl ring planes are deviated from the molecule plane by significant angles (up to $65^{\circ}$ ), which is caused by the Coulomb repulsion between hydrogen atoms of different phenyl rings. This fact is important for understanding that the molecule is characterized by low symmetry $\mathrm{C}_{1}$, whereby all without exception states of the molecule with the same multiplicity exhibit interaction.

Because the molecule is composed of ions, polar solvents, in particular, a mixture of (1:1) methanol and diethyl ether are used for its study. In the absorption spectrum of such an AMG solution, bands at $620 \mathrm{~nm}$ and $465 \mathrm{~nm}$ are observed in the visible region. The bands at $360 \mathrm{~nm}, 310 \mathrm{~nm}$ and $250 \mathrm{~nm}$ are observed in the UV region of the spectrum. Unique to the azides is the presence of AMG fluorescence with a maximum at $708 \mathrm{~nm}$ and a quantum yield of $\eta=0.8$.

Theoretical studies of absorption spectra using quantum-chemical methods MNDO and AM1 give absorption bands, the maxima of which are given in Table 1 . This table shows between which MOs the quantum transition occurs, the wavelength at the absorption maximum, and the oscillator strength for singlet-singlet quantum transitions.

As follows from Table 1, the MNDO calculation method yields results somewhat closer to the experimental ones than the AM1 method. However, experience has shown that there is a linear relationship between the energy of light quanta corresponding to experimental and theoretical data at the maxima of the quanta transitions. Therefore, it is possible to recalculate the theoretical data in a way to better match the experimental data. Theoretical calculation data allow to perform the assignment of absorption bands to the corresponding quantum transitions. 
Table 1 - Singlet-singlet and singlet-triplet quantum transitions in AMG

\begin{tabular}{|c|c|c|c|c|c|c|}
\hline \multicolumn{7}{|c|}{ AM1 calculation method } \\
\hline $\begin{array}{l}\text { Quantum } \\
\text { transition }\end{array}$ & $\mathrm{MO}$ & $\lambda, \mathrm{nm}$ & $\begin{array}{l}\text { Quantum } \\
\text { transition }\end{array}$ & $\mathrm{MO}$ & $\lambda, \mathrm{nm}$ & $\begin{array}{c}\text { Oscillator } \\
\text { power }\end{array}$ \\
\hline$S_{0} \rightarrow T_{1}$ & $70 \rightarrow 71$ & 834.2 & $S_{0} \rightarrow T_{1}$ & $70 \rightarrow 71$ & 514.7 & 0.9256 \\
\hline$S_{0} \rightarrow T_{2}$ & $69 \rightarrow 71$ & 678.8 & $S_{0} \rightarrow T_{2}$ & $69 \rightarrow 71$ & 475.1 & 0.8288 \\
\hline$S_{0} \rightarrow T_{3}$ & $\begin{array}{l}69 \rightarrow 72 \\
68 \rightarrow 71\end{array}$ & 570.3 & $S_{0} \rightarrow T_{3}$ & $\begin{aligned} & 69 \rightarrow 74 \\
& 68 \rightarrow 74\end{aligned}$ & 428.2 & 0.0008 \\
\hline$S_{0} \rightarrow T_{4}$ & $\begin{array}{l}69 \rightarrow 74 \\
68 \rightarrow 74\end{array}$ & 471.1 & $S_{0} \rightarrow T_{4}$ & $\begin{aligned} 69 \rightarrow 79 \\
68 \rightarrow 79\end{aligned}$ & 360.6 & 0.0008 \\
\hline$S_{0} \rightarrow T_{5}$ & $69 \rightarrow 78$ & 440.1 & $S_{0} \rightarrow T_{5}$ & $66 \rightarrow 71$ & 352.3 & 0.0003 \\
\hline$S_{0} \rightarrow T_{6}$ & $\begin{array}{l}69 \rightarrow 79 \\
68 \rightarrow 79\end{array}$ & 420.6 & $S_{0} \rightarrow S_{6}$ & $67 \rightarrow 71$ & 351.5 & 0.0006 \\
\hline$S_{0} \rightarrow T_{7}$ & $67 \rightarrow 71$ & 395.1 & $S_{0} \rightarrow S_{7}$ & $65 \rightarrow 71$ & 347.8 & 0.0022 \\
\hline \multicolumn{7}{|c|}{ MNDO calculation method } \\
\hline $\begin{array}{l}\text { Quantum } \\
\text { transition }\end{array}$ & $\mathrm{MO}$ & $\lambda, \mathrm{nm}$ & $\begin{array}{l}\text { Quantum } \\
\text { transition }\end{array}$ & $\mathrm{MO}$ & $\lambda, \mathrm{nm}$ & $\begin{array}{c}\text { Oscillator } \\
\text { power }\end{array}$ \\
\hline$S_{0} \rightarrow T_{1}$ & $69 \rightarrow 71$ & 980.1 & $S_{0} \rightarrow T_{1}$ & $69 \rightarrow 71$ & 587.6 & 0.7779 \\
\hline$S_{0} \rightarrow T_{2}$ & $\begin{array}{l}69 \rightarrow 72 \\
68 \rightarrow 71\end{array}$ & 723.0 & $S_{0} \rightarrow T_{2}$ & $70 \rightarrow 71$ & 521.2 & 0.0955 \\
\hline$S_{0} \rightarrow T_{3}$ & $70 \rightarrow 73$ & 657.3 & $S_{0} \rightarrow T_{3}$ & $70 \rightarrow 78$ & 449.9 & 0.0005 \\
\hline$S_{0} \rightarrow T_{4}$ & $70 \rightarrow 71$ & 520.0 & $S_{0} \rightarrow T_{4}$ & $\begin{array}{l}70 \rightarrow 73 \\
68 \rightarrow 71\end{array}$ & 407.8 & 0.4784 \\
\hline$S_{0} \rightarrow T_{5}$ & $\begin{array}{l}70 \rightarrow 78 \\
64 \rightarrow 78\end{array}$ & 495.4 & $S_{0} \rightarrow T_{5}$ & $66 \rightarrow 71$ & 393.8 & 0.0005 \\
\hline$S_{0} \rightarrow T_{6}$ & $69 \rightarrow 72$ & 467.3 & $S_{0} \rightarrow S_{6}$ & $65 \rightarrow 71$ & 392.4 & 0.0030 \\
\hline$S_{0} \rightarrow T_{7}$ & $65 \rightarrow 71$ & 461.2 & $S_{0} \rightarrow S_{7}$ & $\begin{array}{l}70 \rightarrow 77 \\
67 \rightarrow 73\end{array}$ & 382.1 & 0.0002 \\
\hline
\end{tabular}

If we denote the AMG molecule by the formula $\mathrm{RN}_{3}$, where $\mathrm{R}$ is a radical of malachite green, the photodissociation reaction is described by the equation

$$
R N_{3} \stackrel{h v}{\rightarrow} R \dot{N} .+N_{2} .
$$

Therefore, in the process of photodissociation, nitrene $R(\dot{N}$. $)$ is formed as the primary product. It has two unpaired electrons localized at different atomic orbitals of the nitrogen atom. In connection with this, the ground state of nitrene is a triplet state. The absorption spectrum of azide (Fig. 1a) differs from the absorption spectrum of nitrene (Fig. 1b) in full accordance with the data of experimental observations. Nitrene, being a reactive molecule, in the absence of molecular oxygen, removes two hydrogen atoms from the solvent $\mathrm{RH}_{2}$, becoming an amine:

$$
R \dot{N} .+R H_{2} \rightarrow R N_{2}+R^{\prime} .
$$

Most likely, in the solvent molecule it is indicated two hydrogen atoms attached to adjacent carbon atoms. In this case, an additional $\pi$-bond will arise between the specified carbon atoms after the transfer of the two hydrogen atoms to the nitrene.

The theoretically calculated absorption spectrum of the amine is shown in Fig. 1c.

If molecular oxygen is present in the solution, it quickly attaches to the nitrene forming a nitrosubstituted a malachite green molecule:

$$
R \dot{N} .+O_{2} \rightarrow R^{N O} O_{2}
$$

According to the experimental data, this molecule has in the absorption spectrum a band shifted to the long-wavelength region relative to the absorption of AMG. As follows from Fig. 1d, the theoretical calculations are consistent with the experimental data.

In experiments of Smirnov and others [6], it is found the dependence of the quantum yield of the photodissociation of the azidogroup in the AMG molecule (Fig. 2). It follows from this figure that the value of the quantum yield is constant in the region of $\lambda<320 \mathrm{~nm}$ and is 0.4 , and decreases from 0.4 to 0.1 with increasing temperature from $77 \mathrm{~K}$ to $300 \mathrm{~K}$. In addition, it has been shown that AMG photoactivity also exists in the visible spectrum, but with a much smaller quantum yield. For this wavelength range, the decrease in the quantum yield of azide photolysis is significantly greater than for the region $\lambda<320 \mathrm{~nm}$ when temperature increases from $77 \mathrm{~K}$ to $300 \mathrm{~K}$.

In order to explain such an unexpected result, the quantum chemical calculations of the energy structure of the excited AMG molecule depending on the length of the dissociating $\mathrm{N}-\mathrm{N}$ bond are made in this work. The optimization of the geometry of the molecule was carried out only for its ground state. No optimization was performed during the $\mathrm{N}-\mathrm{N}$ bond elongation. This means that the energies of the excited states found in the $\mathrm{N}-\mathrm{N}$ bond elongation will be slightly overestimated.

Since the calculation program does not always assign a certain absorption band to the quantum transition, the $\mathrm{N}-\mathrm{N}$ bond elongation step was $0.02 \AA$ each time to ensure the accuracy of the construction of the potential surfaces of the excited AMG states. In this case, the curves of the potential surfaces were clearly manifested (Fig. 3). This calculation was made using the AM1 method. Fig. 3 illustrates the configuration curves shown only to extend the dissociative bond up to $1.83 \AA$. With fur- 
ther elongation, the curves of the singlet and triplet states intersect, moving away by approximately $1 \mathrm{eV}$. Therefore, the $T_{4}$-state of the AMG was transformed into the $T_{0}$-state of the nitrene, and the $T_{1}$-state of the AMG became the $T_{1}$-state of the nitrene.

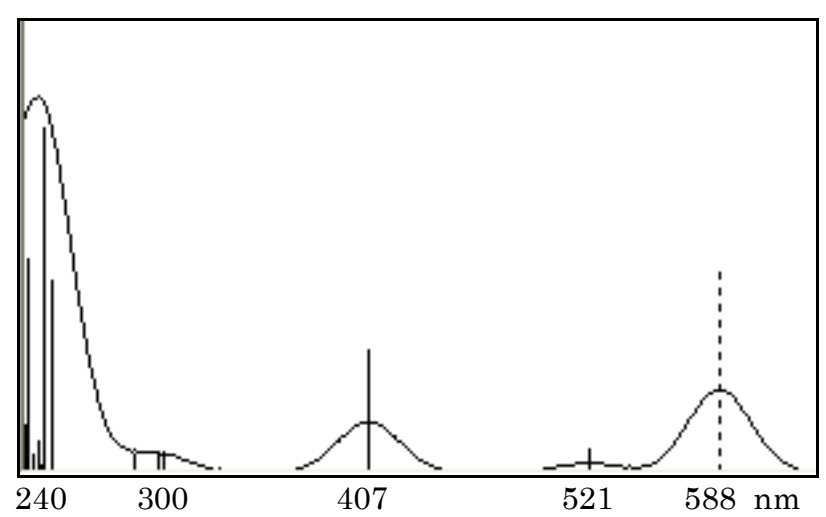

a

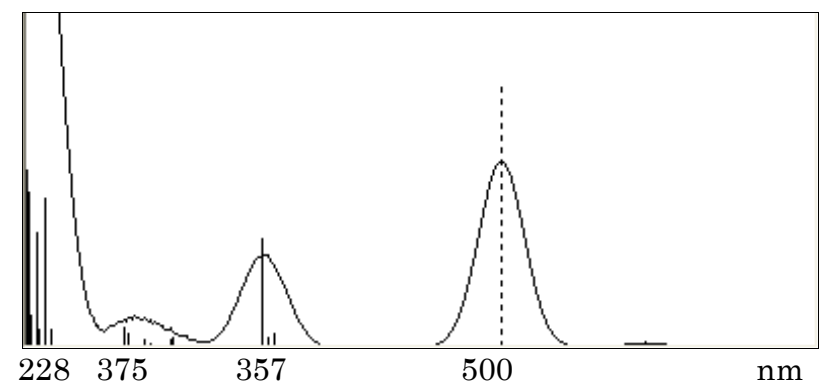

$\mathrm{b}$

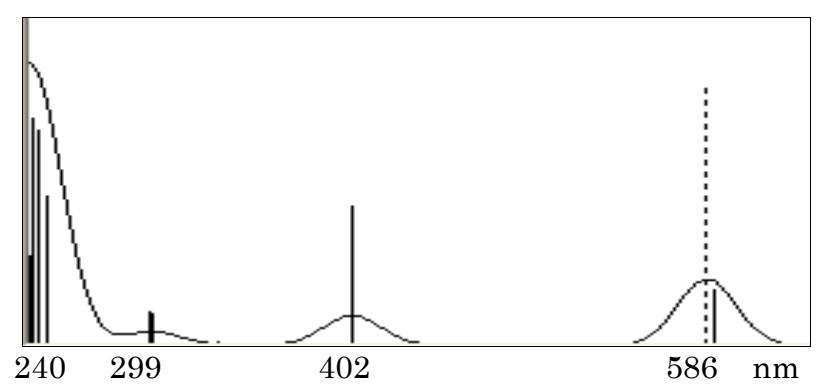

c

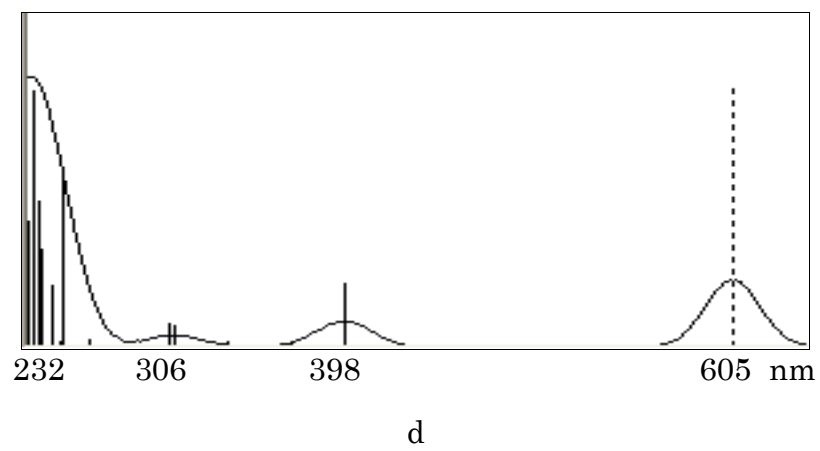

Fig. 1 - The absorption spectra of AMG (a), NMG (b), $\mathrm{NH}_{2}-\mathrm{MG}$ (c) and $\mathrm{NO}_{2}-\mathrm{MG}$ (d) calculated using the MNDO method

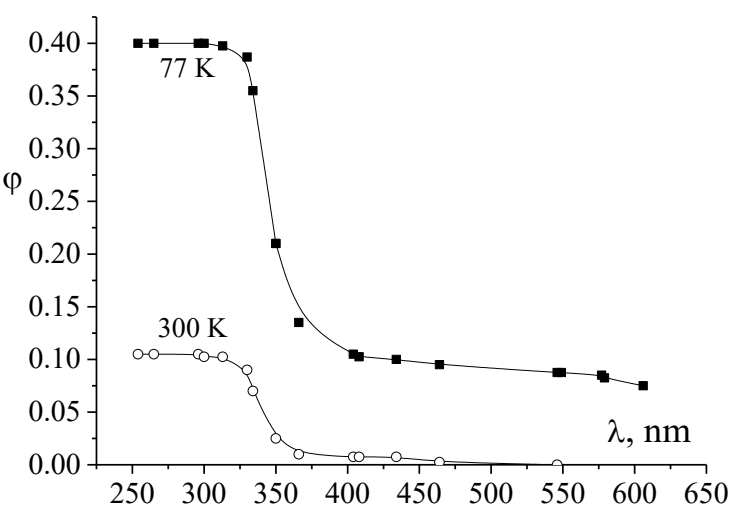

Fig. 2 - Dependence of the quantum yield of AMG photodissociation on the wavelength

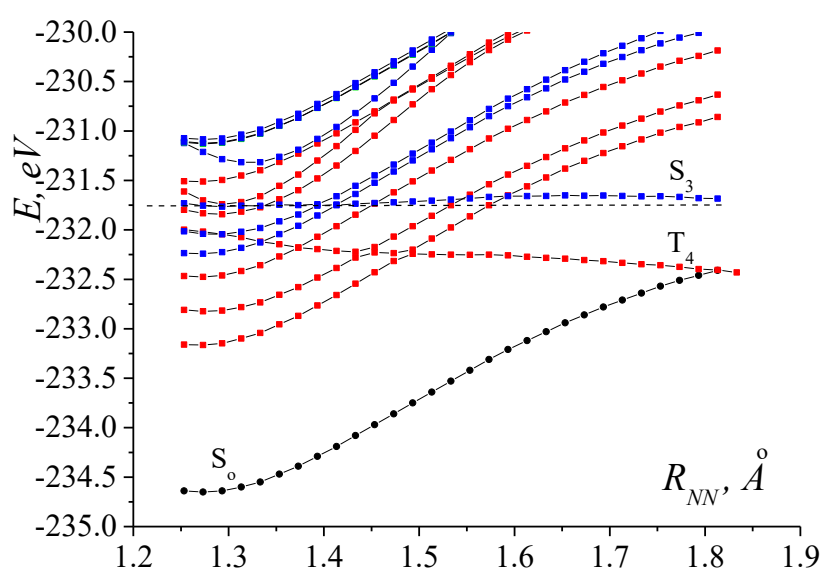

Fig. 3 - AMG energy structure depending on the N-N bond length. Red lines are the configuration curves of the triplet states, blue curves are the singlet excited states

An important difference between the potential surfaces of excited states of substituted phenylazides [1] and AMG is that in this case not only the energy surface of the triplet state is dissociative, but the surface of the excited singlet state too. It follows from Fig. 3 that the energy of the quantum transition to the state $\mathrm{S}_{3}$ slightly increases with the elongation of the $\mathrm{N}-\mathrm{N}$ bond. However, considering given the above information regarding the lack of optimization of the geometry of the AMG when lengthening the $\mathrm{N}-\mathrm{N}$ bond, it becomes clear that in reality $S_{3}$ is dissociative.

As follows from the data in Table 1, the states $S_{3}$ and $T_{4}$ correspond to $\pi \rightarrow \sigma^{-}$quantum transitions between the same MOs. Let us look at the structure of these MOs.

It follows from the MO structure that both occupied $\pi$-MOs have in their structure the contributions of the atomic orbitals of the azido group. On the other hand, unoccupied $\sigma$-MO is completely localized on the azido group. It follows that there is no spatial prohibition on $\pi \rightarrow \sigma^{-}$quantum transition. There is only a significant decrease in extinction in this quantum transition due to the different nature of the MO. 

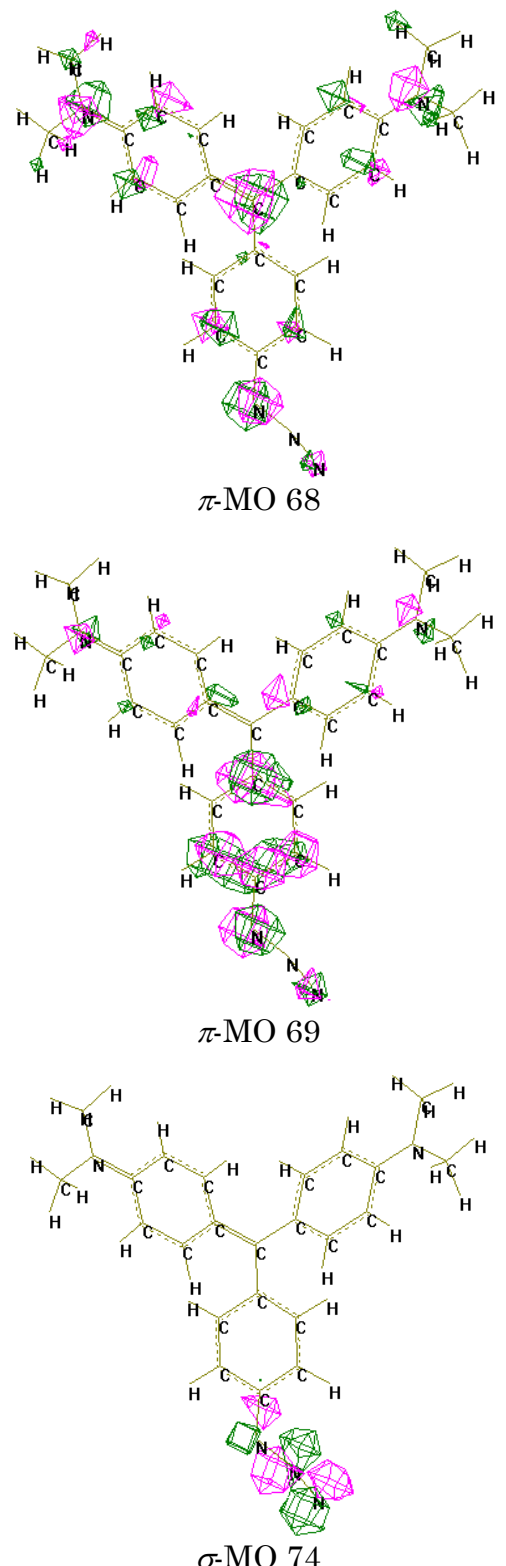

Considering Fig. 3, we notice that at the intersection of the configuration curves of the triplet or singlet states, interaction between them occurs resulting in a small splitting of the corresponding energy levels.

When the wave functions of the energy states have the same symmetry, this leads to the fact that the matrix element of the interaction between the states $i$ and $j \cdot H_{i j}=\int \psi_{i} \hat{H} \psi_{j} d V \neq 0$. Here $\hat{H}$ is the Hamiltonian of the molecule. In this case, to find the energy of the states, the secular equation is written:

$$
\left|\begin{array}{cc}
E_{i}-E & H_{i j} \\
H_{i j} & E_{j}-E
\end{array}\right|=0,
$$

where $E_{i}$ and $E_{j}$ are the energies of the $i$-th and $j$-th MOs, respectively. When the energy distance between states significantly exceeds $H_{i j}$, then

$$
E_{1}=E_{i}+\frac{2 H_{i j}^{2}}{E_{i}-E_{j}}, E_{2}=E_{\mathrm{j}}-\frac{2 H_{i j}^{2}}{E_{i}-E_{j}} .
$$

If at some distance $r$ (intersection point) it turns out that $E_{i}=E_{j}=E_{r}$, then $\left(E_{r}-E\right)^{2}=H^{2}{ }_{i j}$ and $E=E_{r} \pm H_{i j}$. So, at the point of intersection, we will actually have a splitting whose value is $2 \mathrm{H}_{i j}$.

For example, at $r=1.49324 \AA$, the splitting at the intersection of triplet states is $0.042 \mathrm{eV}$, wherefrom the magnitude of the matrix element of the interaction between dissociative $T_{4}$ and $T_{1}$ triplet states is $0.021 \mathrm{eV}$, i.e. $170 \mathrm{~cm}^{-1}$. It is clear that such a cleavage will not affect the dissociation of the molecule from the dissociative triplet state.

With regard to the intersection of the energy surfaces $S_{3}$ and $S_{2}$, the value of the splitting is $0.013 \mathrm{eV}$ $\left(107 \mathrm{~cm}^{-1}\right)$, and then at the intersection of $S_{2}$ and $S_{1}$ the splitting value is reduced to $0.007 \mathrm{eV}\left(56 \mathrm{~cm}^{-1}\right)$. So, these values of splitting correspond to the energy of low energy vibrations of the molecule.

We performed the corresponding calculations of the vibrational spectrum of the AMG and found 150 frequencies, some of which correspond to the vibrations of the molecule that includes the azido group: $67 \mathrm{~cm}^{-1}$, $132 \mathrm{~cm}^{-1}, 137 \mathrm{~cm}^{-1}, 208 \mathrm{~cm}^{-1}, 283 \mathrm{~cm}^{-1}, 296 \mathrm{~cm}^{-1}$, $310 \mathrm{~cm}^{-1}, 389 \mathrm{~cm}^{-1}$ and a number of other oscillations with large quantities of energy. The frequencies of vibrations close in energy will help to effectively overcome the marked energy splitting.

However, there seems to be a more efficient channel that provides relaxation of the excitation of the molecule with the formation of nitrene. We are talking about the uncertainty ratio $\Delta E \cdot \Delta t=h$. For example, for vibrational energy or for a splitting value of $67 \mathrm{~cm}^{-1}$, the oscillation period will be $2 \cdot 10^{-13} \mathrm{~s}$. This time corresponds to the uncertainty of the energy value of $167 \mathrm{~cm}^{-1}$. Therefore, with such uncertainty in the magnitude of the energy, the energy splitting between the excited states will be imperceptible to the electronic system in the process of relaxation to a new state - the nitrite malachite green.

The main channel of relaxation of the excitation energy from the highly excited $\left(S_{2}, S_{3}\right.$, etc.) states is the internal conversion to the $S_{1}$ state. The rate constants of such processes lie within $10^{11} \div 10^{13} \mathrm{~s}^{-1}$. Compared to these processes, internal $\left(S_{1} \rightarrow S_{0}\right)$ and interconversion $\left(T_{1} \rightarrow S_{0}\right)$ processes are relatively slow processes. One reason for the rapid internal conversion to the $S_{1}$ state is a high density of highly excited states, whose potential surfaces often intersect. The reason for the low interconversion rate $T_{1} \rightarrow S_{0}$ and the internal conversion $S_{1} \rightarrow S_{0}$ is a large energy difference between the corresponding states. In this case, the internal conversion rate constant will decrease in accordance with the factor $\exp \left(-\Delta E / \hbar \omega_{\max }\right)[8-10]$.

Here, the value of $\omega_{\max }$ corresponds to the highfrequency limit of the vibrational spectrum. Experimental and theoretical studies have shown that it influences the rate of non-radiative transitions between the energy levels of excited states of a molecule [8-10].

The physical meaning of this factor is that the probability of the process of exchange of the electron excitation energy $\Delta E$ by the oscillating quanta depends on the number of oscillating quanta that are formed at the same time. The more you need to form vibrational quanta, the less the relaxation process is probable. 
Let the nonradiative relaxation time between excited states of the same multiplicity equals $\tau$. The energy difference between the states is $\Delta E$. If the relaxation occurs by exchanging electron energy for the maximum vibrational energy $E_{v}=\hbar \omega_{\max }$ [8], which in our case corresponds to vibrations of the $\mathrm{C}-\mathrm{H}$ group, then the number of vibrations $n=\Delta E / E_{v}$ will arise. Therefore, the excitation residence time near each oscillation is $\Delta t=\tau / n=\tau \cdot E_{\tau} / \Delta E$. Thus, the uncertainty of the magnitude of the electron energy is

$$
\Delta E_{e}=h / \Delta t=\frac{h \Delta E}{E_{i}-E_{j}} .
$$

At a certain amount of oscillation energy, the uncertainty of the electron energy will be equal to the oscillation energy $\left(E_{c r}\right)$. As the vibrational energy increases, the uncertainty of the electron energy will decrease. Therefore, in this case, in the process of relaxation of the excitation energy of the molecule, the electron will feel every step of relaxation and on stationary states will be delayed. As a result, the relaxation process will be quasi-equilibrium. Delay of electron at steady states will promote to flow of the transformation processes of the molecule from these states.

If the vibrational energy is less than the critical energy, then the uncertainty of the electron energy will exceed the vibrational energy and the relaxation process will be non-equilibrium.

For example, if the energy difference between excited states of an electron is $1 \mathrm{eV}$ and $\tau=1 \cdot 10^{-12} \mathrm{~s}$, then the value of the critical energy of the electron

$$
E_{c r}=\sqrt{h \cdot \Delta E / \tau}=2.58 \cdot 10^{-2} \mathrm{eV}=208.5 \mathrm{~cm}^{-1} .
$$

To find out which mechanism of non-radiative relaxation is implemented in our case, we examined the vibrational spectrum of the AMG. To simplify the problem, we considered one fragment of the molecule:

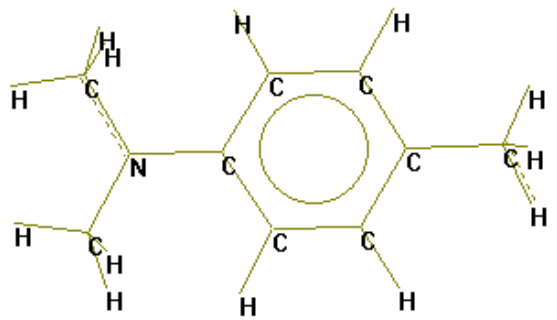

The calculations showed that the maximum frequency in the vibrational spectrum corresponds to the oscillations of $\mathrm{C}-\mathrm{H}$ groups of the phenyl ring and it is equal to $3190 \mathrm{~cm}^{-1}$. The importance of such localization of oscillations with the maximum frequency is that these oscillations can interact with the $\pi$-electron system by exchanging the electron excitation energy for the vibrational energy of individual bonds of the molecule. Since this frequency is an order of magnitude greater than $E_{c r}$, one can conclude: the electron relaxation from highly excited states of the AMG molecule occurs by a quasi-equilibrium mechanism. This allows the electron to linger on the intermediate states, which allows photodissociation of the AMG to occur with the formation of a free molecule of nitrogen and nitrene of malachite green.
Based on the appearance of the factor $\exp \left(-\Delta E / \hbar \omega_{\max }\right)$ it becomes clear that the process of relaxation of the electron excitation takes place mainly in all energy states of the excited molecule. Since the energy distance between the near states depends on the number of the state, the speed of the relaxation process will also be different, but of the same order. At the same time, the rate of $S_{1} \rightarrow S_{0}$ relaxation (the energy of the quantum transition is equal to $\approx 16100 \mathrm{~cm}^{-1}$ ) will be reduced by $\approx 155$ times.

Increasing the temperature of the sample leads to a significant increase in the number of vibrations of $\mathrm{C}-\mathrm{H}$ groups in the AMG, which will significantly accelerate the relaxation processes of the electronic excitation of the AMG molecule. This, in turn, will reduce the quantum yield of AMG photodissociation by the release of a nitrogen molecule.

Excitation of the AMG molecule into the third and higher singlet states of the molecule in the intermediate case leads to the occupation of the state $S_{3}$. From this state, the processes of molecular dissociation and relaxation into $S_{2}$ and $S_{1}$ states are possible by a quasiequilibrium mechanism. It turned out that the state $S_{2}$ intersects with the dissociative triplet state, and therefore can transmit energy to it with the subsequent dissociation of AMG. Excitation localization in the state $S_{1}$ also allows the excitation energy to be transmitted to a dissociative triplet state, although in this case there is a small potential barrier $\left(870 \mathrm{~cm}^{-1}\right)$ substantially smaller than the vibrational energy that provides the non-radiative process. It is imposed on these processes a prohibition of the quantum transition between singlet and triplet states, that together fully explains the dependence of the quantum yield of the AMG photodissociation on the wavelength of the spectral region $\lambda>320 \mathrm{~nm}$.

\section{CONCLUSIONS}

Based on studies of physical and photochemical processes in solutions of para-azidomalachite green (AMG) the following results are obtained:

1. The absorption spectra of AMG are formed by $\pi \rightarrow \pi^{*}$ quantum transitions. There is a weak absorption band $\pi \rightarrow \sigma^{*}$ ( $S_{0} \rightarrow S_{3}$ quantum transition) among the intense absorption bands. It turned out that the corresponding singlet and triplet states of the molecule are characterized by dissociative energy surfaces. Therefore, two channels of photodissociation of the AMG molecule with the release of the nitrogen molecule and the formation of nitrene of the malachite green exist and are manifested in experimental studies.

2 . Theoretical calculations of the absorption spectra of AMG and the products that occur after the photo-dissociation of AMG (nitrene, amine, and nitro-substituted malachite green) have allowed to decipher the absorption spectra recorded in the experimental studies.

3 . It has been shown that nitrene of malachite green actively interacts with the solvent molecules, tearing off two hydrogen atoms from them, and in the presence of molecular oxygen it is bonded with these molecules to form stable products.

4. Theoretical calculations have been carried out, which showed that the processes of relaxation of excita- 
tion of the AMG molecule with the involvement of highfrequency vibrations of $\mathrm{C}-\mathrm{H}$ bonds, localized on phenyl rings, proceed as quasi-equilibrium processes, that is the electronic system in the process of relaxation of excitation stopped at each energy level for a period exceeding the specified oscillation period. This fact provides the possibility of the processes of dissociation of the molecule from the corresponding energy states.

5 . It is shown that with the increase in temperature from $77 \mathrm{~K}$ to $300 \mathrm{~K}$, the role of high-frequency vibrations of $\mathrm{C}-\mathrm{H}$ bonds increases significantly, that leads to an enhanced competitive relaxation process of electronic excitation of a molecule and a decrease in the quantum yield of AMG photodissociation.

6. It is shown that in the spectral region $\lambda>320 \mathrm{~nm}, \pi \sigma^{*}$ triplet state of the molecule is responsible for the process of photodissociation of AMG, which is populated due to singlet-triplet conversion from $S_{2}$ and $S_{1}$ states. This process is characterized by a reduced quantum yield of photodissociation of AMG and a much stronger influence of the temperature rise from $77 \mathrm{~K}$ to $300 \mathrm{~K}$ on the magnitude of the quantum yield.

\title{
REFERENCES
}

1. P.O. Kondratenko, Fotohimichna diya svitla (Kyiv: VPC "Kiyvsky universitet": 2005) [Photochemical action of light] (in Ukrainian).

2. P.A. Kondratenko, Yu.M. Lopatkin, T.N. Sakun, Phys. Chem. Solid St. 8 No 1, 100 (2007).

3. P.O. Kondratenko, Yu.M. Lopatkin, Phys. Chem. Solid St. 5 No 3, 474 (2004).

4. P.O. Kondratenko, Yu.M. Lopatkin, T.N. Sakun, J. NanoElectron. Phys. 4, No 2, 02017 (2012).

5. P.O Kondratenko, T.M. Сакун, Yu.M. Lopatkin, J. NanoElectron. Phys. 4, No 4, 04022 (2012).
6. T.M. Sakun, Relaksatsiyni protsesy u vysoko zbudzhenykh stanakh molekul barunyka. Diss., 150 p. (Odesa: 2012). [Relaxation processes in highly excited states of dye molecules] (in Ukrainian).

7. K. Burke, J. Werschnik, E.K.U. Gross, J. Chem. Phys. 123 , 062206 (2005)

8. V.L. Ermolaev, E.B. Sveshnikova, T.N. Bodunov, PhysicsUspekhi 39 No 3, 261 (1996).

9. V.L. Ermolaev and E.B. Sveshnikova, Acta Physica Polonica A 95 No 3, 299 (1999).

10. E.N. Bodunov, M.N. Berberan-Santos, Opt. Spectrosc. 104 No 4, 540 (2008).

\section{Квазірівноважні процеси релаксації електронного збудження молекули азидомалахітового зеленого}

\author{
П.О. Кондратенко ${ }^{1}$ Ю.М. Лопаткін ${ }^{2}$, Т.М. Сакун ${ }^{1}$ \\ 1 Національний авіаційний університет, пр. Гузара, 1, 03058 Київ, Украӥна \\ ${ }^{2}$ Сулський державний університет, вул. Рилського-Корсакова, 2, 40007 Сули, Украйна \\ Реальні перспективи застосування результатів наукових досліджень для створення елементної \\ бази оптоелектроніки, розробки люмінесцентних датчиків, для оптичного запису інформації є обгрун- \\ туванням актуальності вивчення процесів, пов'язаних з електронними сильно збудженими станами \\ молекул. На підставі проведених досліджень фрізичних та фотохімічних процесів в розчинах пара \\ азидомалахітового зеленого (АМЗ) показано, що спектри поглинання АМЗ формуються квантовими \\ переходами $\pi \rightarrow \pi^{*}$. Серед інтенсивних смуг поглинання ховається слабка смуга поглинання $\pi \rightarrow \sigma$ \\ $\left(S_{0} \rightarrow S_{3}\right.$ квантовий перехід). При цьому виявилось, що відповідні синглетний і триплетний стани мо- \\ лекули характеризуються дисоціативними енергетичними поверхнями, тобто існують і проявляються \\ в експериментальних дослідженнях два канали фротодисоціації молекули АМЗ. Показано, що процеси \\ релаксації збудження молекули АМЗ, які відбуваються з залученням високочастотних коливань С-H- \\ зв'язків, локалізованих на фенільних кільцях, протікають як квазірівноважні процеси, тобто, елект- \\ ронна система в процесі релаксації збудження зупиняеться на кожному енергетичному рівні впро- \\ довж часу, який перевищуе період вказаного коливання. Цей фракт забезпечує можливість протікання \\ процесів дисоціації молекули з відповідних енергетичних станів. 3 підвищенням температури від \\ $77 \mathrm{~K}$ до $300 \mathrm{~K}$ суттево підвищуеться роль високочастотних коливань С-Н-зв'язків, що приводить до \\ значного зменшення квантового виходу фотодисоціації АМЗ як з синглетного, так і з триплетного ди- \\ соціативних станів.
}

Ключові слова: Високозбуджені електронні стани, Фотодисоціація, Квазірівноважні процеси релаксації, Пара-азидомалахітовий зелений, Два канали фротодисоціації молекули. 